\section{EMBRYAIDDLE \\ Aeronautical University}

SCHOLARLY COMMONS

\section{International Journal of Aviation,} Aeronautics, and Aerospace

\title{
Implications of Short Scheduled Ground Times for European Carriers
}

Johannes Waltenberger

Embry-Riddle Aeronautical University, Johannes.waltenberger@gmx.de

Hans-Joachim K. Ruff-Stahl

Embry-Riddle Aeronautical University, ruffha@erau.edu

Follow this and additional works at: https://commons.erau.edu/ijaaa

Part of the Business Administration, Management, and Operations Commons

\section{Scholarly Commons Citation}

Waltenberger, J., \& Ruff-Stahl, H. K. (2018). Implications of Short Scheduled Ground Times for European Carriers. International Journal of Aviation, Aeronautics, and Aerospace, 5(3). https://doi.org/10.15394/ ijaaa.2018.1244

This Article is brought to you for free and open access by the Journals at Scholarly Commons. It has been accepted for inclusion in International Journal of Aviation, Aeronautics, and Aerospace by an authorized administrator of Scholarly Commons. For more information, please contact commons@erau.edu. 
One of the main characteristics of LCCs (low-cost carriers) is short turnaround times (Barret, 2004), which allows these airlines to maximize the number of flights per day and airplane utilization. If these short turnaround times cannot be met, the LCC's on-time performance will suffer. Hence for LCCs, the airtime of their airplanes is seemingly more important than customer satisfaction. Traditional airlines, in turn, allow longer ground times in exchange for better ontime performance and thus happier customers. Good on-time performance is of increasing importance to LCCs too, as they are trying to attract delay-sensitive customers from the business segment (Klophaus, Conrady \& Fichert, 2012). So far, little research has been directed to the comparison between low-cost carriers and traditional airlines regarding on-time performance and scheduled turnaround times.

Jetzki (2009) published the latest and most comprehensive work on this issue, showing differences between low-cost carriers and traditional scheduling models in terms of ground times and the ability to absorb delay. While different strategies to minimize delay amongst different carriers were identified, the company names were not disclosed due to confidentiality reasons. Even after Jetzki's study, it is still unclear whether traditional airlines should change their turn around model to improve efficiency while still maintaining customer satisfaction.

This paper is intended as a first step to close this gap in research by examining airlines' on-time performance, turnaround scheduling practices, and block times exemplarily at Valencia airport and correlating these values to the carriers' financial performance. To avoid confidentiality issues, this is done by using publicly available data from flightradar24.com. Under investigation will be the three industry leaders in European LCC operations, Ryanair (FR), EasyJet (U2), and Eurowings (EW), and for comparison two successful network airlines, Lufthansa (LH) and British Airways (BA).

\section{Review of Literature}

\section{The Business Case of European Low-Cost Carriers}

Over the last three decades, the low-cost segment in Europe's airline business has risen dramatically, gaining a market share of $41 \%$ in 2016 in the EU (Airbus, 2016). Consequently, and for economic reasons, traditional airlines had to adapt their business models and increasingly adopt LCC-type strategies. To differentiate LCCs from traditional airlines, Klophaus et al. (2012) have identified 13 criteria, which are usually found in the low-cost segment: Secondary airport 
usage, point-to-point services only, no code sharing, one-way fares only, no more than one fare at any time, no more than two fares at any time, single class cabin, no complimentary in-flight service with lowest fare category, complimentary inflight service with highest fare category, no free checked baggage with lowest fare category, free checked baggage with highest fare category, no frequent flyer program. If a low-cost airline satisfied all 13 criteria, it reached a reference value of one. Vice versa, if an airline - for example, Lufthansa - scored not a single low-cost criterion, this led to an overall reference value of zero.

While Ryanair scored first with a reference value of one, the average score of all examined 21 European carriers in the year 2012 was 0.54. However, Ryanair has announced to offer connecting flights (Ryanair, 2017) since then and EasyJet started the distribution of tickets through a global distribution system (Sabre, 2016). These examples show that LCCs themselves start shifting their business models toward more traditional ways to earn money in air transportation, mainly through the selection of primary airports and routes and by attracting customers via new fare structures and services.

\section{Maximizing Utilization Through Short Ground Times}

One remaining significant difference between LCCs and traditional airlines is the turnaround of an airplane between landing (precisely: the on-block time of the aircraft) and next takeoff (precisely: the off-block time of the aircraft). The scheduled length of a turnaround is a trade-off between aircraft utilization rate and the ability to absorb delay, thereby maintaining on-time performance. The significant advantage of LCCs in comparison to traditional airlines has always been their ability to turn around aircraft on the ground quicker. This ability leads to higher utilization of the aircraft, as the plane spends comparatively more time in the air through a more substantial number of flights per day (Barret, 2004). Short turnaround times can be achieved by 1) cleaning the cabin between flights by the cabin crew instead of a ground crew, 2) reduced food service on board, and 3) reduced delivery process (if at all), and 4) optimized turnaround procedures (Barret, 2004).

Short ground times are easier to achieve at smaller airports due to shorter taxi times and a by comparison larger number of available gates (Barret, 2004). However, the advantage of short turnarounds decreases with increasing travel distance, as more extended airtime per flight leads to fewer turnarounds per day (Belobaba, 2016). 
The disadvantage of short ground times is the missing slack time that is often used to absorb previously generated delay. This leads to a greater degree of vulnerability to disturbances and therefore delay cascades quickly throughout the system. LCCs seem to be generally less capable of absorbing delay in comparison to other airlines, and Jetzki (2009) pointed out that "every minute of primary delay created more than one minute of reactionary delay for this type of business model" (p. 41). Fricke and Schultz (2009) have investigated turnarounds of traditional Lufthansa operations at Munich and Frankfurt and found that pilots were only able to absorb 4.5 minutes of delay on an average leg length of 79 minutes, which indicates that in-air options for absorbing delay are insufficient.

In contrast to traditional airlines, LCCs are usually scheduling shorter ground times to increase aircraft utilization rates, even at the cost of lower ontime performance and a large portion of reactionary delay.

\section{The Costs of Delay}

Low on-time performance values are generally considered undesirable because they generate costs for airlines and passengers alike with an enormous impact on the economic performance of an airline. Cook and Tanner (2015) found that 15 minutes of delay at the gate usually cost $550 €$ for an A320 or a B738, two aircraft models frequently used by LCCs. These values roughly double for enroute delays, for example, due to arrival management at busy airports or for re-routing due to air traffic flow management (ATFM) regulations.

While many aspects of delay can be calculated easily through input variables such as crew and fuel costs, maintenance, and reactionary delay factors, other aspects such as passenger cost remains a vague guess. Cook and Tanner (2015) differentiate between 'hard costs' such as rebooking, compensation, and care and 'soft costs' including passenger dissatisfaction and customer disloyalty.

Counterintuitively, early arrivals may also be costly for airlines as gates may be still blocked. Hao and Hanson (2013) estimate costs for early arrivals to be below the costs for delays, but still considerable for airlines when planning their schedules. Cook (2007) indicated that "just five minutes of unused buffer, atgate, for a B767-300ER, would amount to well over $€ 50,000$ over a period of one year, on just one leg per day" (p. 118). While this aircraft type is much larger than the types usually used by European low-cost carriers, the example illustrates the importance of on-time performance and adequately scheduled block times, which will be discussed in the following section. 
In sum, any form of positive or negative delay will result in additional costs for an airline. However, late arrivals and the associated reactionary delay will generate considerably more costs for airlines than early arrivals. Those early arrivals may be planned as idle times for crew and aircraft and may help to absorb previously generated delay. Depending on the specific situation of serviced airports, early arrivals may be useful to prevent the build-up of delay.

\section{The Importance of Managing Block Times}

Delay is always associated with cost. Hence, the scheduling of appropriate block times is of great importance to minimize the build-up of delay. Hao and Hansen (2013) have demonstrated that ample block time scheduling is a powerful tool to improve an airline's on-time performance - however at the cost of efficiency and utilization rates. For new routes, airlines at first estimate the required block time in advance based on flight plans. As soon as actual data is gathered, most airlines adopt the scheduled block time accordingly. Block time setting techniques vary. Some airlines set a single block time for a specific route for an entire year, while other carriers consider seasons of the year, days of the week, and time of the day.

Even though LCCs increasingly converge their business models toward traditional airlines in Europe, their on-time performance still lags behind traditional carriers, and there are no indications that LCCs strive to close this gap and improve their on-time performance (Flightontime.info, 2017). It seems that from an economic standpoint, a lower on-time performance overall outweighs the associated costs. Hence, it is the purpose of this study to evaluate whether there is still a difference between the on-time performance of LCCs and traditional airlines. As a case study, this study will examine the scheduled turnaround times, and block-time setting practices at Valencia airport (VLC) and correlate the findings to the airlines' financial performance.

\section{Method}

This quantitative study sought to determine if the economic gains of lower on-time performance of low-cost carriers outweigh the costs. The following data were analyzed to evaluate such costs and benefits.

\section{Flight Data}

Data for flights operated by Ryanair, EasyJet, Eurowings, Lufthansa, and British Airways to and from the airport of Valencia (Spain) was retrieved from 
flightradar24.com. The airport was selected for two reasons: First, it is located in a region that is frequently visited by travelers from northern Europe and is, therefore, a destination for LCCs and traditional airlines alike. Second, the number of flight movements is large enough to expect a sufficiently large data set. Finally, the flight time between the airport and several northern European Destinations is approximately the same (DUS, FRA, LGW, LTN, MUC, STR: $113-131$ minutes), which is relevant for the evaluation of block times. Data were retrieved for July, August, and September 2017.

The data may be expected to be highly reliable due to the method used by flightradar24.com collecting the data. Errors are expected to be within $+/$ - one minute due to the quick changes in airspeed, altitude, and position during takeoff and landing. Besides reliability, the validity of the data may be considered high for flight times between the airports. For some calculations, average taxi times were added to average flight times to calculate average delay and block times. Duration and delay were converted into minutes and analyzed through an ANOVA.

Table 1

Formulas

departure delay

$=$ Actual takeoff time $($ ATT $)-$ standard departure time (STD)

arrival delay

scheduled turnaround $=$ Actual landing time $($ ATL $)-$ standard arrival time (STA) time $=$ Scheduled departure time STD (subsequent flight) scheduled arrival time (STA) (preceding flight)

actual ground time $=$ Actual departure time (ATD) (subsequent flight) actual arrival time (ATA) (preceding flight)

scheduled block time $\quad=$ STA - STD

Note. All results are calculated in minutes. Delay is positive when aircraft are late.

\section{Financial Data}

Financial Data was retrieved from the respective annual reports of all carriers (British Airways plc., 2017; EasyJet, 2016; Lufthansa, 2017; Ryanair, 2016) as available for the financial year 2016. On-time performance was only reported by Ryanair, and data was completed through numbers from an OAG (2016) report for the other carriers.

Possible major one-off effects mentioned in the annual reports were corrected and the data was then organized along with the operational performance 
indicators in a table to allow easy comparison for the reader. Due to the definition of the financial year for all carriers, no data was available to match the study period with current numbers from the summer 2017 season.

\section{Hypothesis}

It is hypothesized that the economic gains of lower on-time performance of low-cost carriers outweigh the costs.

\section{Results}

The findings revealed significant differences among the various carriers, however not along the lines between low-cost-carriers and traditional airline models. Significant differences were found for on-time performance, turnaround scheduling strategies, actual turnaround lengths, and block-time calculations.

\section{On-Time Performance}

In this section, the actual takeoff-times of all carriers were compared through statistical analysis. Figure 1 and Table 2 show the results and indicate that there are two groups of airlines, which are not divided by the traditional separating line that was expected to be found between low-cost and non-low-cost operations.

The first group consists of the two legacy airlines British Airways and Lufthansa, as well as Ryanair as a quite punctual base operator at VLC. Eurowings and EasyJet make up the second group with a significantly lower ontime performance, which was confirmed through an ANOVA analysis with $F(4$, $1052)=51.91, p<0.0001$. A post hoc Tukey HSD test (see table A2) revealed that the differences between Ryanair and Lufthansa, between Ryanair and British Airways, between Lufthansa and British Airways, and between EasyJet and Eurowings were not significant. All other comparisons between the carriers showed significant differences in on-time departure performance.

Similar results regarding statistical significance were found for the arrival delays of flights originating from VLC. Only Ryanair and Lufthansa touched down on average before their scheduled on-block time. All other carriers seemed to operate on average late on their routes from Valencia. 


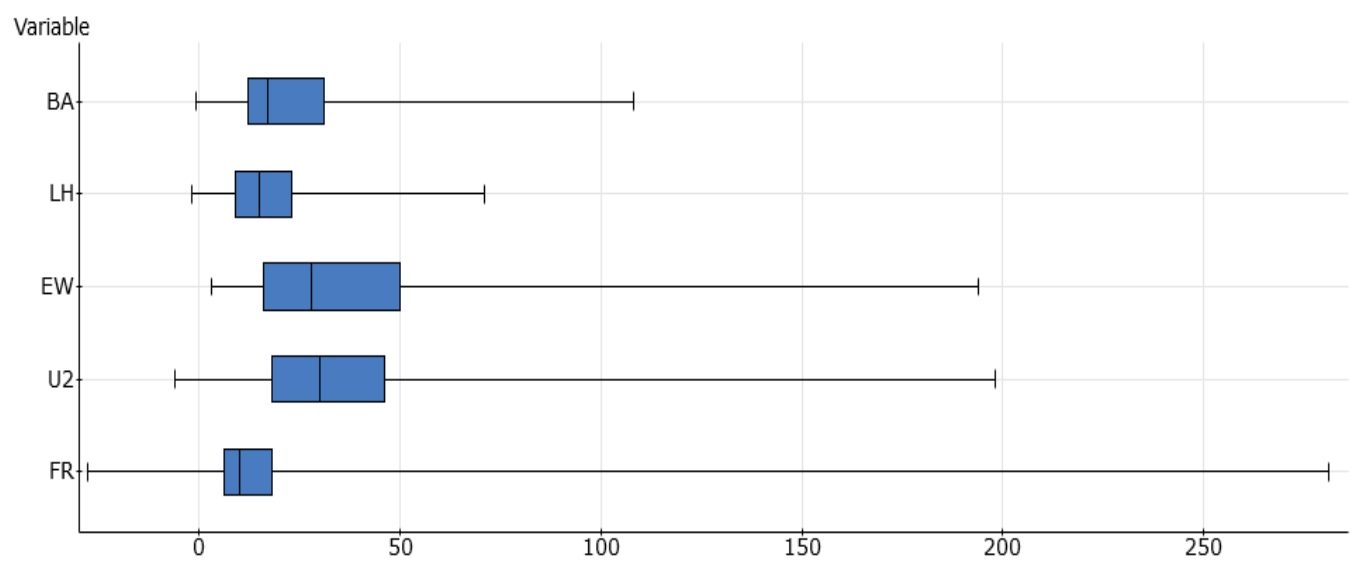

Figure 1. Boxplot of departure delay for flights leaving from VLC. Whiskers identify extreme values.

Table 2

Delay for Flights Departing from VLC

\begin{tabular}{|c|c|c|c|c|c|c|c|}
\hline \multirow[b]{2}{*}{ Carrier } & \multirow[b]{2}{*}{ Abbreviation } & \multirow[b]{2}{*}{$\mathrm{n}$} & \multicolumn{2}{|c|}{ Departure Delay } & \multicolumn{2}{|c|}{ Arrival Delay } & \multirow{2}{*}{$\mathrm{M}_{\mathrm{D}}-\mathrm{M}_{\mathrm{A}}$} \\
\hline & & & $M_{\mathrm{D}}$ & $S D$ & $M_{\mathrm{A}}$ & $S D$ & \\
\hline Ryanair & FR & 300 & 17.1 & 27.5 & -1.5 & 28.2 & 18.6 \\
\hline EasyJet & $\mathrm{U} 2$ & 310 & 38.5 & 31.4 & 22.5 & 32.3 & 16.0 \\
\hline Eurowings & $\mathrm{EW} / 4 \mathrm{U}^{\mathrm{a}}$ & 143 & 37.7 & 31.8 & 19.7 & 34.5 & 18.0 \\
\hline Lufthansa & LH & 229 & 18.3 & 14.3 & -6.1 & 13.6 & 24.4 \\
\hline British Airways & $\mathrm{BA}$ & 75 & 25.7 & 22.2 & 2.8 & 22.4 & 22.9 \\
\hline
\end{tabular}

Note. All results are calculated in minutes. Delay is positive when aircraft are late.

${ }^{a}$ Germanwings (4U) was included because it operates exclusively as a contractor for EW.

\section{Turnarounds}

As noted earlier, a quick and efficient turnaround is key to high equipment productivity, and thus a primary component of the current low-cost strategy. Therefore, turnarounds at VLC airport were compared for on-time performance above. Because only STA (standard time of arrival), ATL (actual landing time), STD (standard departure time), and ATT (actual takeoff time) were available, the calculation of the actual turnaround times required a two-step process. In a first step, average taxi-in $(M=4, S D=2)$ and taxi-out times $(M=11, S D=4)$ from summer 2016 were added to the actual landing time (ATL) and subtracted from 
the actual takeoff time (ATT) of each flight. Average taxi times were retrieved from EUROCONTROL (2016a, 2016b) and are depicted in Table A1.

In a second step, early arrivals that were still early after the addition of taxi-in time were set to schedule on-block time for further data evaluation. This was necessary to count only those turnarounds as longer-than-scheduled that exceeded the scheduled off-block time. Otherwise, an aircraft that arrived ten minutes early at the gate would have been considered late regarding scheduled turnaround time, even if it left five minutes before scheduled off-block time. The results are depicted in Table 3, which indicates significant differences among the different airlines for scheduled turnaround lengths and actual durations.

Table 3

Scheduled and Actual Turnaround Times at VLC

\begin{tabular}{|c|c|c|c|c|c|c|c|c|}
\hline \multirow[b]{2}{*}{ Carrier } & \multirow[b]{2}{*}{$\mathrm{n}$} & \multicolumn{3}{|c|}{ Scheduled } & \multicolumn{3}{|c|}{ Actual $^{\mathrm{a}}$} & \multirow[b]{2}{*}{$M_{\mathrm{S}}-M_{\mathrm{A}}$} \\
\hline & & $M_{\mathrm{S}}$ & $S D$ & Median & $M_{\mathrm{A}}$ & $S D$ & Median & \\
\hline Ryanair & 207 & 54.9 & 35.9 & 45 & 50.4 & 33.5 & 39 & 4.5 \\
\hline EasyJet & 310 & 35.0 & 0 & 35 & 47.0 & 16.6 & 42 & -12.0 \\
\hline Eurowings & 143 & 40.0 & 0 & 40 & 49.5 & 19.2 & 44 & -9.5 \\
\hline Lufthansa & 139 & 49.2 & 4.2 & 50 & 50.2 & 9.9 & 49 & -1.0 \\
\hline \multicolumn{2}{|c|}{ British Airways 75} & 46.7 & 3.8 & 45 & 55.8 & 17.4 & 50 & -9.1 \\
\hline
\end{tabular}

Note. All turnarounds included other than night stops.

${ }^{a}$ Actual turnaround times were calculated by subtracting early arrivals and average taxi times from the actual ground time.

The method for data retrieval for Ryanair as the only home-based carrier in this study allowed the calculation of some additional information, which was not available for the other airlines. Out of a total of 92 days, the virtual FR aircraft completed six legs on 59 days and eight legs on only 29 days during that period. The average flight time was 97 minutes. Long turnarounds seemed to coincide quite often with necessary crew-changes, for example after two or four legs at home-base.

\section{Block Times}

Hao and Hansen (2013) pointed out the correct set of scheduled block times to minimize costs for airlines. Therefore it was expected that all airlines 
operating to and from VLC would set block times in a similar manner because the expenses for this procedure are expected to be low in comparison to the mentioned costs of positive and negative delay in the literature review.

Average scheduled block times (ASBT) were calculated and compared to the sum of the average flight time and the average taxi-in, and taxi-out time at the respective airports (Table A1), which represent average actual block times (AABT). The difference between AABT and ASBT was calculated for each citypair, and a weighted average was then retrieved for every carrier. Ryanair was excluded from the calculations due to the relatively small number of flights operated on each route it offers from VLC. The carrier conducted a maximum of 20 flights on the VLC-SCQ route (and vice versa), a number that was deemed too small to calculate a meaningful average. In contrast to the assumptions based on Hao and Hansen (2013), the differences among the four carriers are large and the setting of scheduled block times seems to have different importance to each of the carriers, as the results in Table 4 indicate.

EasyJet (U2) achieved the lowest weighted average in this study due to the good fit of the scheduled block times for the route between LGW (London Gatwick) and VLC, which was only one minute off for both directions. The routes from and to LTN (London Luton) included more generously scheduled block times, but due to the smaller number of flights, the impact on the weighted average was limited. U2 is the only carrier in this study that used scheduled block times, which varied depending on daytime and weekday.

Due to the limited number of considered routes for this case study, data may differ considerably on other routes operated by the airlines. However, trends are most probably observable for all routes and without much doubt, the type of scheduled block times (variable/fixed) is constant over the whole network.

\section{Financial Performance and Key Markers}

The financial performance of all three low-cost carriers differed significantly in the financial year 2016. FR achieved the highest absolute profit and was at the same time able to reach the largest profit margin (26.4\%). This was partially due to a one-off "gain of $€ 317.5$ million on the sale of the Company's . . . shareholding in Aer Lingus" (Ryanair, 2016, p. 95). In contrast, EasyJet reached a significantly lower profit per passenger and per aircraft, which also resulted in a lower, but still, impressive profit margin (14.6\%) compared to other players in the industry. Eurowings is the only carrier in this study, which was not able to reach profitability in 2016. The company was restructured lately and profits are spread 
over a large network of affiliated companies and airlines that cooperate with Eurowings (Lufthansa Group, 2017). Results are displayed in Table 6.

Table 4

Block Time Comparison

\begin{tabular}{|c|c|c|c|c|c|c|c|}
\hline Airline & City Pair & $\mathrm{n}$ & ASBT & AABT & Delta $^{a}$ & Type $^{\text {b }}$ & $\begin{array}{l}\text { Wt } \\
\text { Avg }\end{array}$ \\
\hline \multirow[t]{4}{*}{$\mathrm{U} 2$} & LGW-VLC & 271 & 139 & 138 & 1 & variable & \multirow{4}{*}{0.7} \\
\hline & VLC-LGW & 271 & 148 & 149 & -1 & variable & \\
\hline & LTN-VLC & 39 & 151 & 145 & 6 & variable & \\
\hline & VLC-LTN & 39 & 148 & 143 & 5 & variable & \\
\hline \multirow[t]{4}{*}{$\mathrm{EW}$} & DUS-VLC & 91 & 150 & 144 & 6 & fixed & \multirow{4}{*}{5.3} \\
\hline & VLC-DUS & 91 & 140 & 143 & -3 & fixed & \\
\hline & STR-VLC & 52 & 140 & 127 & 13 & fixed & \\
\hline & VLC-STR & 52 & 140 & 129 & 11 & fixed & \\
\hline \multirow[t]{4}{*}{ LH } & FRA-VLC & 183 & 140 & 136 & 4 & fixed & \multirow{4}{*}{4.5} \\
\hline & VLC-FRA & 181 & 145 & 140 & 5 & fixed & \\
\hline & MUC-VLC & 49 & 140 & 138 & 2 & fixed & \\
\hline & VLC-MUC & 48 & 140 & 133 & 7 & fixed & \\
\hline \multirow[t]{2}{*}{ BA } & LGW-VLC & 75 & 145 & 136 & 9 & fixed & \multirow{2}{*}{7.0} \\
\hline & VLC-LGW & 75 & 150 & 145 & 5 & fixed & \\
\hline
\end{tabular}

Note. All times are calculated in minutes.

${ }^{\mathrm{a}}$ Delta $=$ ASBT - AABT; Negative numbers indicate an overshoot of the scheduled block time.

${ }^{\mathrm{b}}$ The type field indicates if block times are scheduled with a fixed length (fixed) or if variation (variable) occurs depending on the time of the day or other variables.

${ }^{\mathrm{c}}$ Weighted average 
Table 6

Financial Performance of LCCs and network airlines in FY2016

\begin{tabular}{|c|c|c|c|c|c|}
\hline Carrier & $\mathrm{FR}^{\mathrm{a}}$ & $\mathrm{U} 2^{\mathrm{a}}$ & $\mathrm{EW}^{\mathrm{a}}$ & $\mathrm{LH}^{\mathrm{a}, \mathrm{e}}$ & $\mathrm{BA}^{\mathrm{a}}$ \\
\hline Profit Margin & $21.5 \% \mathrm{~b}$ & $14.6 \%$ & $<0^{\mathrm{f}}$ & $7.4 \%^{\mathrm{f}}$ & $12.1 \%$ \\
\hline Load Factor & $92.8 \%$ & $91.6 \%$ & $79.6 \%$ & $79.1 \%$ & $81.2 \%$ \\
\hline $\begin{array}{l}\text { On-time Performance } \\
\text { (STA + } 15 \text { minutes) }\end{array}$ & $>90 \%$ & $75 \% \mathrm{c}$ & $\begin{array}{l}4 \mathrm{U} 91 \%^{\mathrm{c}} \\
\mathrm{EW} 90 \%^{\mathrm{c}}\end{array}$ & $82.4 \% \mathrm{c}$ & $78.4 \%^{\mathrm{g}}$ \\
\hline Profit Before Tax [million] & $1,404 €$ & $405 £$ & $-91 €^{d}$ & $1,135 €^{\mathrm{d}}$ & $1,566 £$ \\
\hline Per PAX & $13.20 € \mathrm{~b}$ & $6.77 £$ & $<0$ & $18.18 €$ & $35.19 £$ \\
\hline Per aircraft [million] & $4.01 €^{\mathrm{b}}$ & $1.93 £$ & $<0$ & $3.24 €$ & $5.34 £$ \\
\hline
\end{tabular}

${ }^{a}$ All data extracted from respective business reports (Ryanair, 2016, EasyJet, 2016, Lufthansa, 2016, British Airways Plc.,2017) unless otherwise stated. ${ }^{\mathrm{b}}$ Corrected by the one-off effect of Air Lingus shares sale. ${ }^{c}$ Datum from OAG (2016) ${ }^{\mathrm{d}}$ adjusted EBIT (EBT not reported). ${ }^{\mathrm{e}}$ Lufthansa Passenger Airlines including regional partners ${ }^{\mathrm{f}}$ EBIT Margin ${ }^{\mathrm{g}}$ Datum Oct 16 to Sep 2017 from OAG (2017)

\section{Discussion}

The on-time performance results are in line with the research conducted by Jetzki (2009) who noted that "one low-cost carrier notably runs on a different strategy" (p. 58), without naming the airline. After the results presented above, this airline can now be identified as Ryanair with the utmost probability. And unexpectedly, the results do not indicate that LCCs calculate more delay than other airlines. At Valencia airport, Ryanair shows even better on-time performance than traditional carriers.

While Ryanair enjoys the reputation of turning around aircraft in 30 minutes or less, the data obtained at VLC indicate differently. Here, Ryanair completed 509 turnarounds other than night stops, with a mean duration of 40 minutes $(M d n=30, S D=31.9)$. This means that half of their turnarounds must have been planned to last more than 30 minutes. In fact, at VLC there was not a single instance in which an aircraft from their fleet was scheduled to be turned around within 30 minutes for two consecutive turnarounds, and half of their turnarounds at VLC were scheduled to last more than 45 minutes.

It is remarkable that Ryanair, rated as the most low-cost-orientated carrier by Klophaus et al. in 2012, did not plan the expected short turnaround times at VLC. Instead, Ryanair used scheduling practices, which are closer to those used 
by Lufthansa and British Airways than other low-cost carriers. This indicates that Ryanair's good on-time performance may a result of considerably longer scheduled turnarounds in comparison to their LCC-competitors.

In comparison, Ryanair is the only carrier that completed its turnarounds on average faster than scheduled, with Lufthansa following second. With a median of 45 minutes for scheduled turnaround times, Ryanair, along with Lufthansa (50 minutes) and British Airways (45 minutes) differs considerably from other LCCs such as Easy Jet and Eurowings. On average and remarkable due to the associated costs, Ryanair flights arrived early. Arriving early allowed Ryanair to effectively absorb delay built during turnarounds at VLC, thus achieving good on-time performance values at this airport.

In general, carriers may decide to either trade on-time performance for higher utilization rates or accept lower airtime per airplane and day in exchange for better punctuality and customer satisfaction. Ryanair seems to prioritize being on-time, while EasyJet seems to accept a delay to achieve better utilization rates.

Eurowings and EasyJet came in last regarding on-time performance. In contrast to all other airlines, Eurowings was not able to depart early in a single instance; hence, turnaround procedures and practices seem to differ significantly from those used by Ryanair. In fact, Eurowings spent on average ten minutes longer at the parking position than intended. However, an evaluation of block time settings did not reveal any strategic reasoning behind this delay.

Ryanair mastered the two-fold trade-off problem between aircraft utilization and on-time performance best by combining the company's ability to turn around aircraft quickly with efficient scheduling, which allows sufficient ground time to absorb delays and operational disturbances. In contrast, EasyJet had the largest overshoot of scheduled turnaround times due to tightly scheduled block times, which led to a considerably lower on-time performance.

The success of these various ground operations strategies can ultimately only be measured in economic terms. Out of the three LCCs in this study, Ryanair is the most profitable company. In contrast, Easy Jet exhibits similar load factors as Ryanair and an albeit lower (nevertheless impressive) profit margin but shows significantly lower on-time performance.

Eurowings, in turn, underwent a restructuring process in 2016 and its parent company Lufthansa is still investing considerable amounts of money to enable the growth of this LCC in the highly competitive European low-cost 
market. Due to these circumstances, Eurowings was not profitable in 2016, and no correlations between financial performance and its operational strategy can yet be made.

The two hub-and-spoke airlines Lufthansa and British Airways, which were included in this paper for similar reasons, reached a lower profit margin in 2016 along with significantly lower load factors than the LCCs. However, both companies generated an overall more profit per passenger than any of the lowcost airlines. This may be due to their large long-haul fleets and the associated higher prices customers are willing to pay for their services - to include reliable on-time performance. However, as this study has shown, the alleged better ontime performance of traditional carriers may be nothing more than a myth.

The hypothesis that the gains of lower on-time performance of low-cost carriers outweigh the associated costs must be rejected based on the results found for Ryanair and Easy Jet. While both airlines reach high-profit margins, Ryanair operates more profitable and shows higher on-time performance values at the same time. Apart from that, the findings of this study support the theory that hybridization of the European low-cost sector, which was first proposed by Klophaus et al. in 2012, has advanced to an operational level: LCCs become increasingly sensitive toward customer satisfaction.

Overall and on an operational level, economic success seems to be associated with the ability of an airline to turn around aircraft quickly, to build schedules that incorporate realistic ground and block times with enough buffer to absorb delay, and the associated high on-time performance to satisfy customers.

\section{Limitations and Recommendations for Future Work}

There are some limitations associated with this study and recommendations for future work may be derived from most of these. The most significant limitation is the close focus on VLC airport, which does not allow gaining a larger picture of operational strategies. Only Ryanair's operation was captured through the tail tracking methodology first introduced by Kondo (2008), and the results were promising. This methodology seems to provide a useful tool for a larger analysis of several airlines and airports over an extended time.

Ryanair performed quite well over the period under evaluation, but it remains unclear if the operation from VLC as a home base had an impact on ontime performance and turnaround times, a topic that requires further investigation. Also, the number of flown legs per day was only captured for FR, and further 
evaluation of the other carriers is necessary to gain an insight into average leg lengths and scheduling strategies. This may have a considerable impact on the strategy, utilization rate, and personnel requirements.

Ryanair was found to leave before STD in some times, a case that was only found in rare circumstances in the data of other carriers. This gives reason to suspect that the turnaround strategy of Ryanair may be somewhat different in comparison to the strategies of all other airlines and may add to the successful performance.

\section{Conclusion}

The clear line between low-cost and non-low-cost airlines has become blurred through the hybridization of the European low-cost market. The observed differences between low-cost carriers compared to traditional airlines were small regarding on-time performance, turnaround scheduling, block-time setting, and turnaround performance at VLC airport. Ryanair's two-fold strategy as the most successful European low-cost carrier consists of the ability to perform short turnarounds while allowing a generously planned schedule at the same time, which overall results in better on-time performance. EasyJet, in turn, focuses on maximizing aircraft utilization through optimized block-time setting, thereby accepting a lower on-time performance.

It is likely that the hybridization of the low-cost sector will eventually force traditional airlines to follow the business models of their low-cost competitors. Consequently, the line between low-cost and traditional airlines will be further dissolved. 


\section{References}

Aron, A., Coups, E. J. \& Aron, E. (2011). Statistics for the Behavioral and Social Sciences: A Brief Course. Upper Saddle River, NJ, USA: Pearson Prentice Hall.

Barrett, S. D. (2004). How do the demands for airport services differ between full-service carriers and low-cost carriers? Journal of Air Transport Management, 10(1), 33-39.

Belobaba, P. (2016). Airline operating costs and measures of productivity. In P. Belobaba, A. Odoni, \& C. Barnhart (Eds.), The global airline industry (pp. 127-187). Chichester, U.K: John Wiley \& Sons.

British Airways Plc. (2017). Annual report and accounts year ended 31 December 2016. Retrieved from phx.corporateir.net/External.File?item=UGFyZW50SUQ9NjYzMTY0fENoaWxkSUQ9 MzcwNDUzfFR5cGU9MQ==\&t=1

CAA. (2017). Punctuality statistics 2016. Retrieved from https://www.caa.co.uk/Data-and-analysis/UK-aviation-market/Flightreliability/Datasets/Punctuality-data/Punctuality-statistics-2016/

Cook, A. (Ed.). (2007). European air traffic management: principles, practice, and research. Burlington, VT, USA: Ashgate Publishing, Ltd.

EasyJet. (2016). Investing in our strengths - Annual report and accounts 2016. Retrieved from http://corporate.easyjet.com/ /media/Files/E/Easyjet/pdf/investors/resultcenter-investor/annual-report-2016.pdf

EUROCONTROL. (2012). The manual. Airport CDM implementation. Retrieved from https://www.eurocontrol.int/sites/default/files/publication/files/2012airport-cdm-manual-v4.pdf

EUROCONTROL. (2016a). Summer 2016 taxi-in Times [Data file]. Retrieved from http://www.eurocontrol.int/sites/default/files/content/documents/officialdocuments/facts-and-figures/coda-reports/taxi-in-times-s16.xlsx 
EUROCONTROL. (2016b). Summer 2016 taxi-out Times [Data file]. Retrieved from

http://www.eurocontrol.int/sites/default/files/content/documents/officialdocuments/facts-and-figures/coda-reports/taxi-out-times-s16.xlsx

Flightontime.info. (2017, September 29). Scheduled airlines. Retrieved from http://www.flightontime.info/scheduled/scheduled.html

Flightradar24. (2017a). How it works. Retrieved from https://www.flightradar24.com/how-it-works

Flightradar24. (2017b). Frequently asked questions. Retrieved from https://www.flightradar24.com/faq

Fricke, H., \& Schultz, M. (2009, June). Delay impacts onto turnaround performance. In ATM Seminar.

Hao, L., \& Hansen, M. (2013, June). How airlines set scheduled block times. In 10th USA/Europe Air Traffic Management Research and Development Seminar, Chicago IL.

Jetzki, M. (2009). The propagation of air transport delays in Europe. PhD diss., Department of Airport and Air Transportation Research RWTH, Aachen University.

Klophaus, R., Conrady, R., \& Fichert, F. (2012). Low cost carriers going hybrid: Evidence from Europe. Journal of Air Transport Management, 23, 54. doi: 10.1016/j.jairtraman.2012.01.015

Kondo, A. (2008). Delay propagation: Tail-number tracking methodology. Presentation. In Institute for Operations Research and the Management Sciences (INFORMS) Annual Meeting.

Lufthansa Group. (2017). Lufthansa annual report 2016. Retrieved from https://investorrelations.lufthansagroup.com/fileadmin/downloads/en/financialreports/annual-reports/LH-AR-2016-e.pdf

OAG Aviation Worldwide Limited. (2017). On-time performance results for airlines and airports. Retrieved from http://www.oag.cn/wpcontent/uploads/2017/01/PunctualityReport2016.pdf 
OAG. (2017). Airport and airline star ratings. Retrieved from https://www.oag.com/on-time-performance-star-ratings

Ryanair. (2016). Annual report. Retrieved from https://investor.ryanair.com/wpcontent/uploads/2016/07/Ryanair-Annual-Report-FY16.pdf

Ryanair. (2017). Connecting flights launched at Rome Fiumicino. Retrieved from http://corporate.ryanair.com/news/connecting-flights-launched-at-romefiumicino/

Sabre. (2016). Sabre continues to support easyJet's growth with business travellers. Retrieved from https://www.sabre.com/insights/releases/sabrecontinues-to-support-easyjets-growth-with-business-travellers/ 


\section{Appendix}

Table A1

Average Taxi-In and Taxi-Out Times for selected Airports

\begin{tabular}{|c|c|c|c|c|c|c|}
\hline \multirow{2}{*}{ Airport } & \multicolumn{3}{|c|}{ Taxi-In } & \multicolumn{3}{|c|}{ Taxi-Out } \\
\hline & $\mathrm{M}$ & $\mathrm{SD}$ & Median & $\mathrm{M}$ & SD & Median \\
\hline DUS & 5 & 2 & 5 & 12 & 4 & 11 \\
\hline FRA & 9 & 4 & 8 & 14 & 6 & 13 \\
\hline LGW & 7 & 4 & 7 & 20 & 9 & 19 \\
\hline LTN & 6 & 3 & 5 & 15 & 9 & 13 \\
\hline MUC & 6 & 2 & 5 & 12 & 8 & 12 \\
\hline STR & 5 & 3 & 5 & 10 & 5 & 10 \\
\hline VLC & 4 & 2 & 4 & 11 & 4 & 10 \\
\hline
\end{tabular}

Note. All results are in minutes. Data was retrieved from EUROCONTROL (2016a, 2016b) for the summer 2016.

Table A2

ANOVA Comparison of Departure Delay including post-hoc Tukey HSD results

Tukey's HSD Comparisons

\begin{tabular}{lccccccc} 
Airline & $n$ & Mean & $S D$ & FR & U2 & EW & LH \\
\hline FR & 300 & 17.1 & 27.5 & & & & \\
U2 & 310 & 38.5 & 31.4 & $<.0001$ & & & \\
EW & 143 & 37.7 & 31.8 & $<.0001$ & 0.9978 & & \\
LH & 229 & 18.3 & 14.3 & 0.9841 & $<.0001$ & $<.0001$ & \\
BA & 75 & 25.7 & 22.2 & 0.0904 & 0.0021 & 0.0161 & 0.2297 \\
\hline
\end{tabular}

Note. All results are in minutes. 